\title{
Class Management under the Environment of New Media
}

\author{
Chengxia WU ${ }^{1, a}$, Hui $\mathrm{LI}^{1, \mathrm{~b}}, \mathrm{Na} Z \mathrm{ZENG}^{1, \mathrm{c}}$
}

\author{
${ }^{1}$ School of Mathematics and Statistics, Central China Normal University, Wuhan 430079, China \\ a47861807@qq.com, bdelia1013@163.com, ' $1171279489 @ q q . c o m$
}

Keywords: new media; class management; class construction; the internet

\begin{abstract}
With the constant progress and development of society, we have already stepped into the Information Age, in which a variety of emerging new media has trickled into people's real life. All kinds of online study such as online teaching and online tutoring have become an important tool for students to study after class. It's also an important way for them to broaden horizons and increase knowledge. In our study, we carried out research and analysis to 50 classes, and discovered that new media is exerting a growing influence on the enhancing of class management and class construction as a convenient and efficient communication tool. We found that it can be improved the class management efficiency, building equal and harmonious relationship between teachers and students and creating the platform for connection between home and school. However, every coin has two sides. As well as providing convenience for class management, new media has posed a great challenge for students to weigh its advantages and disadvantages.
\end{abstract}

\section{Introduction}

The 21 century has entered the age of new media. We should keep pace with the times and make full advantage of the new media to open up a new situation for class management and construction, and apply the Internet to promote it. Focusing on new media, this paper starts from presenting the theme and introducing the research significance, namely, the necessity and feasibility of research into class management under the environment of new media. Then it states the present situation of class management by using new media and has an analysis of the problems and deficiency. Finally, the principles which need to be paid attention to in applying new media to class management are pointed out, followed by a summary of how to make the profit of managing class by new media to the fullest.

\section{Research background of class management under the environment of new media}

\subsection{Presentation of the theme}

Class management is the core task of a person who's in charge of managing class, which requires the manager to cultivate the students by taking appropriate measures and means according to the expectations and requirements of the school or society so as to make students have healthy personality, get full and all-round development, and become useful talents[1]. Nowadays online information develops so rapidly that people's life gets greatly influenced, and the school is no exception. The new media online are not limited to time or space and have shortened the distance between people. So the openness and richness of them get the unanimous acceptance and application among wide students and teachers. The arrival of Internet Age requires teachers to adjust educational method up-to-date by combining with the traditional class management mode in their task of managing the class.

\subsection{The deficiency of traditional class management mode}

Traditional class management in China has formed a rather mature system[2]. However, with the development of the times, the disadvantage of traditional class management is becoming increasingly prominent. For example, the instructor informs students of things in the coming week at the evening roll call once a week in university. However, it's unavoidable that there are students not able to be present for some reason. And information delivered verbally through the filtration of brain can't be kept in mind with time going on, which makes much information be ignored and many activities get across incompletely, thus students' gaining of information is not guaranteed. It 
means that students accept the resources of information passively and cannot bring their activity into play, which limited their personality development greatly. While the new media online can give students a choice to filter information on their own and find information beneficial to themselves so that their potentials and creativity can be fully developed.

We compared the differences in 50 classes of traditional and new media class management, and use of the past five years the number of changes in the new media class management.

\section{Changes in the number of classes for using new media in the past five years}

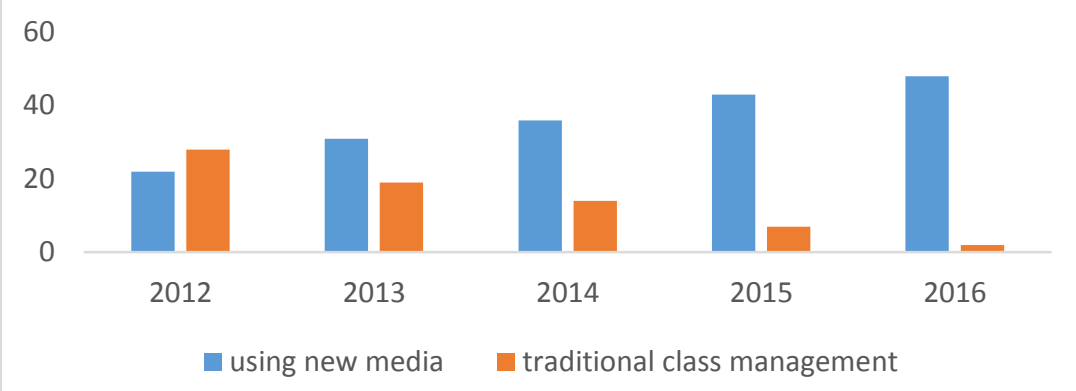

Fig1. Changes in the number of classes for using new media in the past five years

\subsection{The necessity of researching into class management under the environment of new media[3]}

Due to the Internet's breakthrough in the limitations of time and space, students and teachers can communicate and interact with each other by means of online new media tools. It makes the relationship between students and teachers develop in a harmonious and equal way. Using the online new media as the way for notification and collection of feedback information enhances the efficiency of managing class.

The appearance of online new media brings new management mode and channel for class managers. However, besides the convenience, it also brings some negative effect. For example, students experience mental shock when they accept information casually under the unknown circumstances. And many criminals would use new media and pretending as a role in class management to cheat students. Students often fall for it because they are less sophisticated and lack social experiences. So it's necessary for us to carry out in-depth research into this issue and explore better ways to use new media in class management.

\section{The influence of new media on class management}

\subsection{Improvement of class management efficiency by using new media}

When applied to class management, modern network resources and technology can help managers deal with daily routine work and improve the working efficiency. And new media is the product and reflection of modern network technology. Using new media to manage class is of help to reduce the work burden of teachers and promote the efficiency of class management drastically. For instance, the creation of class QQ group can send important message and notification promptly[4]. The group file can provide materials for students to download whatever is useful for them. And the group photo album can restore the photos of class activities and keep the precious memories of everyone. Moreover, the group voting enables students to express their opinions towards the decision of the teacher or the class manager by vote. Another example is creating official accounts on We Chat to propagandize the class spirit and class motto and improve students' ideological and moral qualities. In addition, the promotion on micro blog enhances class prestige and influence as well[5]. Since the network has openness and richness and has no time and space limitation, messages can get sent wherever and whenever with a rapid spreading speed, and the correct information can get updated in time. However, if teachers assemble students in class to inform them, it not only wastes much time and energy, but also makes the information easy to 
forget after a certain period of time and has no recordings to search for, which is both troublesome and has no real effect.

\subsection{Building equal and harmonious relationship between teachers and students}

The function of online communication on the internet platform breaks the limitations of time and space and makes the communication and exchanging between people easier and more relaxed. Moreover, the relationship between teachers and students becomes harmonious and equal. Chen Jingyun emphasizes the importance and skills of online communication in "The online communication skills and art of youths".

New media can set teachers free from the tedious work and enable them to finish daily work with high efficiency so that they can leave more time and room to communicate with students. And students can give their opinions or express their inner trouble or entanglement to the teacher via QQ or email. If they have psychological barrier, they can even express by sending anonymous messages. In this way, students will no longer be afraid to express their comments or opinions due to embarrassment or shyness. And if they have any psychological problem, it can get solved in time. By observing the dynamic condition of students' moment on WeChat, the teacher can learn students' phycology. By giving comments, an interacting communication is achieved. Thus the relationship between teachers and students become equal and mutual respect between them also forms, which is good for students' healthy growth and then a harmonious class can be built.

\subsection{Creating the platform for connection between home and school[6]}

Children are always the apple of the parents' eye and the obsession that they can't get rid of most. However, due to the geographical limitations, students often return home every half year of even once a year, their parents know little about their life. As the distance grows farther and because of the space limitation, the parent-child relationship becomes weak. The richness and openness of university life broadens students' vision so much while the parents' relative feudal thoughts run in the opposite direction of their children's; so students often feel the communication barrier between them and their parents. While on the parents' side, they also feel that the children's self-awareness grows stronger as they grow up. So a more reasonable way should be found to seek the balance point between university students and their parents.

Geographical limitation leads to communication only by means of telephone between parents and teachers. Yet teachers also have busy work to deal with so that they can't keep a good contact with every parent, which makes parents know little about the detailed study and recent development condition of their children. Actually we can make good use of new media to build a platform for communication between home and school, and provide a platform for parents' consultation and communication without being hindered by space and time limitation. The creation of QQ group can be regarded as the platform for communication between home and school, which is responsible for answering the parents' consultation and inquiry. Students' current situation can be sent to the group file and group album photo as well. It enables the parents to supervise the students to finish their various tasks, keep a close contact with their children and pay attention to the healthy growth of their mentality, which can not only strengthen the connection between parents and teachers, but also help them know the current activities of their children, fully understand the thoughts of their children and comprehend the mentality of their children so that they can better communication and contact with each other, thus the parent-child relationship can also be better developed.

In 50 classes in our survey, we found that the use of new media are becoming diversified manner, and increasing in the number, the new media that build on home-school platform also played a great effect. 


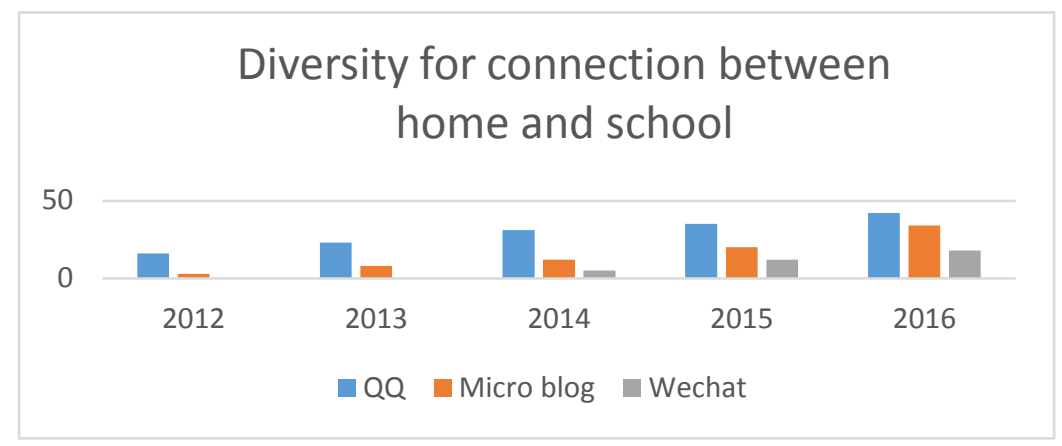

Fig2. Diversity for connection between home and school

\section{The problems of applying new media to class management}

Students often use mobile phones and are easy to be dependent on the Internet. Playing games or chatting in class would leave their study uncultivated and the precious time for them to learn knowledge and master skills is also wasted. And the internet is filled with much negative information that hasn't been filtered, which has an influence on students' physical and mental health development. Besides, online communication without too much concerning enables students to talk whatever they want. While it limits students' communication skills when they communicate and interact with others in real life. It results in a phenomenon of pouring out words unceasingly online while keeping silent in real life.

New media online is also characterized most by its openness, which offers chance for some criminals to cheat university students who are young and haven't fully developed their mentality so they can't distinguish the false information and easily trust others and then be cheated. Many QQ groups would be mixed with some people who are already out of school and working in society, so students who are lacking in judgment would be involved. For example, someone who introduces part-time jobs asks students to offer the broker fee while it later turns out that the information is false and has no follow-up. Another example is those who spread the tiny ads also enable students to fall for it and they squeeze students with payment by installment and personal loan. Or there are people conducting fraud by stealing others’ QQ and WeChat accounts.

\section{How to use online new media correctly in class management}

\subsection{Systematization of class management}

The traditional class management is often accompanied by class rules and class regulation to restrain students' behavior, which also acts as the standard and principle for students to evaluate their own behaviors. So using online new media to manage class should also build normative systematization management. For instance, setting group leader and manager to manage group members can firmly prevent outside people who have other intentions from mixing in the class group and spreading negative information to take illegal action. The group leader can manage the group file, notify messages timely and update the group photo album and so on. Meanwhile, the manager of class official account on We Chat and micro blog should also notify the current situation of class in time and spread other messages and notifications, trying their best to make all the students in class get useful information for them.

\subsection{Adhering to human-oriented democratic management}

The original intention of using new media in class management is to better serve the students, mange the class, and create good class atmosphere to achieve the aim of enabling students' healthy growth. So what we should do is adhere to the human-oriented democratic management, put students at the principle position all the time, regard students' willingness as the object of all the activities and fit students' thoughts and opinions. Thus, the teacher can't go his or her own way in class management. And the class manager also shouldn't make sweeping generalizations. Instead, they should communicate well with students, seek for opinions widely and let everybody discuss mutually to reach a conclusion. In addition, students' feedback channel should be free and open. 
Through students' active participation in all the things, participation-based management mechanism would be strengthened and perfected.

\subsection{Education of network security knowledge}

New media enjoys its superiority in managing class, yet is also accompanied by its negativity meanwhile. University students' knowledge of network security is not enough, they should constantly watch out for the information given out by the Internet. As class managers, we should remind students of keeping their personal information, raising their vigilance towards online information, avoiding trust in strangers blindly and going deep into unknown information by various means such as group announcement. What's more, we should also publicize legal case of network fraud in class QQ group, on WeChat and microblog, and improve the safety awareness of students through case analysis of network security.

\section{References}

[1]Xianmei Wei, Kun Han. On the Class Management Strategies of the Head Teacher[A]. Information Engineering Research Institute, USA. Proceedings of 2014 2nd International Conference in Humanities, Social Sciences and Global Business Management(ISSGBM 2014 V25)[C].Information Engineering Research Institute, USA:,2014:4.

[2]Zhang zhiyong, Xue Yansong. Discussion on The Implementation of The Credit System in Institutions for Higher Education[A]. Intelligent Information Technology Application Association. Proceedings of the 2011 2nd Asia-Pacific Conference on Wearable Computing Systems (APWCS 2011) and 2011 International Conference on Intelligent Control and Information Technology (ICICIT 2011 V4)[C].Intelligent Information Technology Application Association:,2011:3.

[3] David Rae, Naomi Woodier-Harris. International entrepreneurship education: Postgraduate business student experiences of entrepreneurship education[J]. Education + Training. 2012 (8)

[4]Gehuang. Class qq group passed class management "positive energy" in English[J]. young teachers,2014,03:30-32.

[5]Guangyu Peng. Design and Implementation of Wechat Marketing System on Web Mode[A]. International Informatization and Engineering Associations, Atlantis Press. Proceedings of 2015 International Conference on Education Technology, Management and Humanities Science(ETMHS 2015)[C].International Informatization and Engineering Associations,Atlantis Press: 2015: 4.

[6] Aundrea C Wilson. The Effects of Web-based Communication and Contact on Parental Involvement.2005 